\title{
Assessing functional ability is important
}

GPs pride themselves on taking a holistic view of their patients, and moving from a strict biomedical to a biopsychosocial perspective. This includes moving from seeing diagnosis and treatment in purely medical terms, to include how the patient is able to function and live in society, as outlined in the WHO International Classification of Functioning, Disability and Health (ICF; Figure 1). ${ }^{1}$ For example, with a patient who has had a stroke one may consider the disease (a clot or bleed in the brain), the impairment (weakness of the left arm and leg), limitation of function (difficulty climbing the stairs), and restriction of participation in society (such as being able to work).

The ICF model stresses the importance of environmental factors (such as whether there is a stairlift at work) and personal factors (such as personality and depression). Moreover, there is not a linear relationship between impairment and restriction, and we have all known patients with apparently minor impairments (such as a skin condition affecting the face) causing them to live a very restricted life, and others with very major impairments who are working and living very full lives. With some patients, such as those with functional somatic syndromes, there is not a clearly definable underlying disorder or disease. ${ }^{2}$

The role of a good GP is to be able to look at these different levels, often simultaneously. However, the majority of medical endeavour, including in general practice, continues to be concentrated on the biomedical model, looking at the underlying disorder or disease. The main drive to improve chronic disease management in UK general practice in the last 5 years has been the additional funding available to practices through the Qualities and Outcomes Framework (QOF). ${ }^{3}$ The clinical aspects are based on measurements for 16 different diseases. Although major causes of physical disability such as stroke and COPD are included, there are no points given for assessment of function, let alone social assessment. The points for stroke, for example, are given for prevention of future attacks (measuring blood pressure and cholesterol, and prescribing of antiplatelet drugs) rather than for ensuring the best care for the current disability.

While there are persuasive arguments against adding even more conditions to the QOF, it is striking that osteoarthritis, the most common cause of physical disability, particularly in older people, is currently not included. A paper in this month's journal shows that it is feasible to develop a series of indicators of quality for osteoarthritis treatment in UK primary care, including assessment of functional status and of pain. ${ }^{4}$ Levels of achievement for these two indicators were low, although higher levels were achieved for patients with severe forms of the disease.

There are simple questionnaires that can be used to assess functional ability. For example, the Health Assessment Questionnaire, originally developed by rheumatologists for arthritis but applicable to other physically disabling conditions, assesses activities of daily living in eight domains. ${ }^{5}$ It is easily selfcompleted by patients within 4 to 5 minutes and takes a minute or less to score. It is useful in the assessment of ability to work, and has also been successfully used in primary and secondary care to predict the eligibility of patients to receive welfare benefits: Disability Living Allowance and Attendance Allowance. ${ }^{6}$ Another paper in this month's journal emphasises the importance of focusing on activities of daily living in patients with end-stage COPD. ${ }^{7}$

Within the mental health domain, there is evidence of a somewhat broader perspective within the QOF. There are points given for assessment of severity in patients with depression using a validated self-completion questionnaire, and for screening (albeit using a simplistic two questions) for depression in patients with diabetes and coronary heart disease. There is also reward for producing a care plan for patients with schizophrenia and dementia.

A major factor reducing the ability of GPs to make good assessments of their patients' functional ability is the lack of support from other health professionals apart from nurses. In hospital departments, such as rheumatology, geriatrics, and stroke care, there are physiotherapists, occupational therapists, and speech and language therapists whose focus is on function (both assessment and treatment) rather than disease. They work closely together and meet with doctors regularly to discuss patients in multidisciplinary team meetings. It would be very helpful if these professionals were similarly integrated within primary healthcare teams. A recent opportunity has been lost, despite the increase of these professionals in the community through the development of intermediate care services, to prevent hospital admissions or facilitate early discharge. These new teams are geographically remote from general practices, and do not usually include doctors, thereby discouraging direct working together with GPs, many of whom may be unaware of the potential of their roles. ${ }^{8}$

One of the main times that it is vital for GPs to consider functional ability is when considering patients' fitness for work. In the UK, GPs are responsible for certifying unfitness to work (and entitlement to both employers and state sickness benefits) from after the first week (when the patient can self-certify) until 28 weeks. Responsibility for certification then moves to the Department of Work and Pensions for Incapacity Benefit or the recently introduced Employment and Support Allowance. Although the GP has to put a diagnosis on the sickness certificate, guidelines from the Department of Work and Pensions clearly emphasise the assessment for work should be based on 


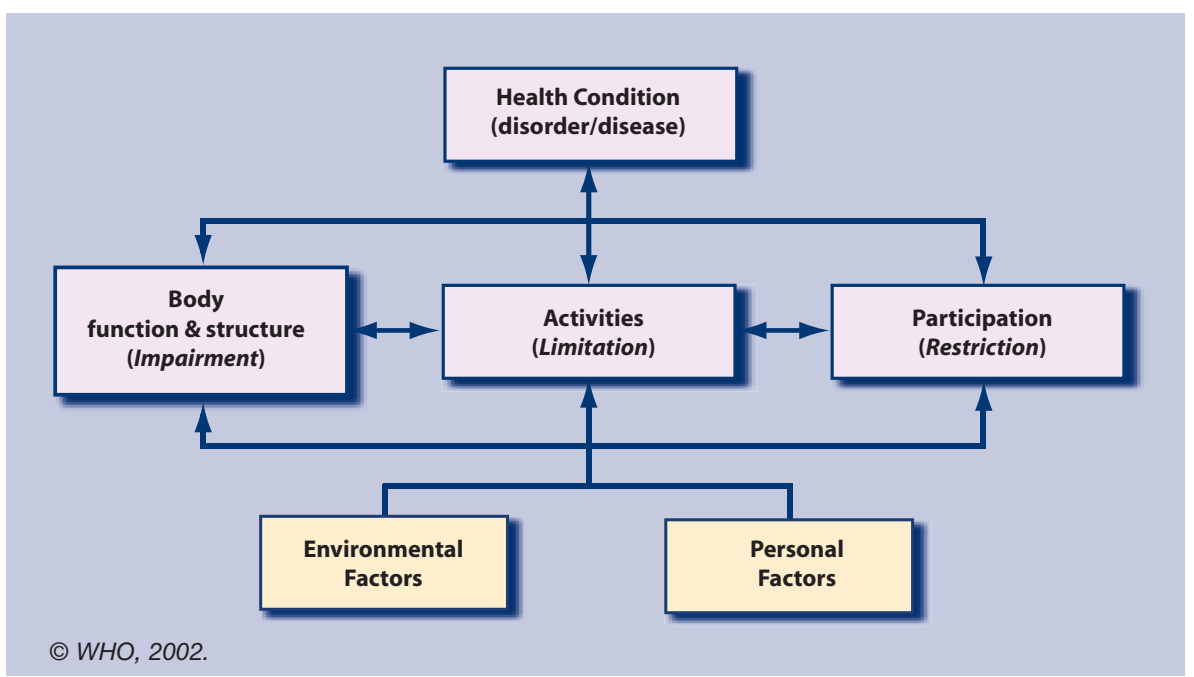

Figure 1. WHO International Classification of Functioning, Disability and Health. ${ }^{1}$

functional ability rather than on the specific disease. $^{9}$

An article in this month's journal from Norway, which has a similar social welfare system to the UK, used focus groups to explore what GPs understand by functional ability. ${ }^{10}$ The GPs emphasised the importance of physical ability, although social functioning was also recognised as significant. They felt uncomfortable assessing ability to work if there was not a clear diagnosis of disease. Whereas they felt able to make simple assessments of physical function, they found assessing the relationship between functional ability and work demands particularly taxing, as they felt it was outside their area of expertise. They also felt less comfortable assessing mental ability. This is particularly relevant, given that $40 \%$ of sick notes given by GPs are for mild mental disorder, ${ }^{11}$ and high levels of depression are seen in people with physical disability. It is interesting that the issues highlighted by the GPs closely mirror the different levels of functioning in the ICF model (Figure 1).

The difficulties that GPs have certifying their patients as sick and helping them back to work were recently highlighted by a UK government report Working for a Healthier Tomorrow. ${ }^{12}$ The amount of money paid in the UK to sick and disabled people who cannot work exceeds $£ 60$ billion each year, and the total cost including lost productivity, estimated at $£ 100$ billion per year, exceeds the annual budget of the NHS. It is also important because research has shown that working is good for both physical and mental health. ${ }^{13}$

Among the report's suggestions are a better system of sickness certification that concentrates on what people can do, rather than what they cannot do, and much earlier access for GPs to rehabilitation services, physiotherapy, and cognitive behaviour therapy. It emphasises the needs for GPs to have greater training in this area and much better liaison with improved state occupational health services. The report's findings have been endorsed by a Healthcare Professionals' Consensus Statement by organisations including the Royal College of General Practitioners. ${ }^{14}$ I hope that this will lead to a much higher profile within general practice of issues relating to functional assessment and treatment, and that this will extend beyond issues of work to include older people and all those with chronic disabling conditions.

\section{David Memel,}

Senior Teaching Fellow, Academic Unit of Primary Health Care, University of Bristol, Bristol.

\section{REFERENCES}

1. World Health Organization Towards a common language for functioning, disability and health ICF. Geneva: WHO, 2002. http://www.who.int/classifications/

icf/training/icfbeginnersguide.pdf (accessed 4 Nov 2008).

2. Wade DT, Halligan PW. Do biomedical models of illness make for good healthcare systems? BMJ 2004; 329(7479): 1398-1401.

3. BMA and NHS EmployersQuality and Outcomes Framework Guidance for GMS Contract 2008/9. London: BMA and NHS Employers, 2008.
4. Broadbent J, Maisey S, Holland R, Steel N. Recorded quality of primary care for osteoarthritis: an observational study. Br J Gen Pract 2008; 58(557): 839-843.

5. Kirwan J, Reeback J. Stanford Health Assessment Questionnaire modified to assess disability in British patients with rheumatoid arthritis. Brit J Rheum 1986; 25(2): 206-209.

6. Langley C, Memel DS, Kirwan JR, et al. Using the Health Assessment Questionnaire and welfare benefits advice to help people disabled through arthritis to access financial support. Rheumatology 2004; 43(7): 863-868.

7. Habraken JM, Pols J, Bindels PJE, Willems DL. The silence of patients with end-stage COPD: a qualitative study. Br J Gen Pract 2008; 58(557): 844-849.

8. Federation of Medical Royal Colleges. Medical aspects of intermediate care. Report of a working party. London: Royal College of Physicians, 2002.

9. Chief Medical Adviser, Department for Work and Pensions. Medical evidence for statutory sick pay, statutory maternity pay and social security incapacity benefit purposes - a guide for registered medical practitioners. London: Department Work and Pensions, 2004.

10. Krohne K, Barge S. How general practitioners in Norway conceptualise functional ability: a focus group study. $\mathrm{Br} \mathrm{J}$ Gen Pract 2008; 58(557): 850-855.

11. Shiels C, Gabbay MB, Ford MF. Patient factors associated with duration of certified sickness absence and transition to long-term incapacity. Br J Gen Pract 2004; 54(499): 86-91.

12. Black C. Working for a healthier tomorrow. London: The Stationery Office, 2008.

13. Waddell G, Burton AK. Is work good for your health and well-being? Norwich: The Stationery Office, 2006.

14. Health Work Wellbeing. Healthcare Professionals' Consensus Statement. Statement of Health and Work. http://www.workingforhealth.gov.uk/documents/healthc are-professionals-consensus-statement-4-march2008.pdf (accessed 4 Nov 2008).

DOI: 10.3399/bjgp08X376159

\section{ADDRESS FOR CORRESPONDENCE}

\section{David Memel}

Academic Unit of Primary Health Care, University of Bristol, 25 Belgrave Road, Bristol, BS8 2AA.

E-mail: david.meme/@bristol.ac.uk 